\title{
OPTIMALISASI EMIS \\ DALAM PROSES DATA BASE PENDIDIKAN DINIYAH DAN PONDOK PESANTREN DI KEMENTERIN AGAMA KABUPATEN BANGKALAN
}

\author{
Savira Rahmania, Agus Ainul Yakin, Elvira Rohadatul Aisy \\ UIN Sunan Ampel, Surabaya - Indonesia | rahmaniasavira@gmail.com
}

\begin{abstract}
Abstrak: Education Management Information System (EMIS) is an education management information system to support planning and policy making in Islamic-based education programs. EMIS is a program that also provides real data to support policy makers. Technology and information as data collection bases have a very important role in supporting the achievement of educational goals. With the existence of EMIS, it is hoped that the incoming data can be more accurate and continuously updated so that it can be used as a basis for decision making. This study aims to determine the optimization of EMIS in the process of data base for diniyah education and Islamic boarding schools in the Ministry of Religion, Bangkalan Regency. As EMIS is an education database, it is hoped that the incoming data will be more accurate and updated to make it easier to find information. However, the Diniyah education and Islamic boarding schools in the Ministry of Religion, Bangkalan Emis Regency have not been able to be used optimally. One of these factors is that there are still many human resources who do not fully understand how to operate an EMIS, so that there are still many institutions that have not filled in the existing data on EMIS. The method used by the researcher is descriptive qualitative method, while the data collection technique uses interviews, observation and documentation.
\end{abstract}

Keywords: EMIS, data dase, Islamic boarding school early education.

\section{Pemdahuluan}

Dunia saat ini sedang berada pada era digital dimana semua akses harus menggunakan internet, era digital sendiri merupakan era komunikasi dan informasi berbasis teknologi komputer. Sejalan 
dengan era digital yang sangat pesat informasi kini menjadi sumber daya yang sangat meningkat. Perlu disadari bahwa informasi sangat penting bagi sebuah organisasi untuk mencapai tujuan pendidikan.

Kementerian Agama telah menggunakan sistem informasi manajemen (SIM) pendidikan yang diharapkan menjadi solusi untuk kemajuan lembaga-lembaga pendidikan yang berada di bawah naungan Kementerian Agama. Sistem informasi manajemen Pendidikan tersebut diharapkan mampu menampung dan mengolah data serta menghasilkan informasi yang tepat dan akurat setiap saat. Teknologi dan informasi memiliki hal yang penting dalam dunia pendidikan untuk mendapatkan data yang real serta data yang diperbaru dalam tahun ke tahun dengan begitu informasi yang ada terus terupdate.

Sistem pendataan EMIS satu-satunya instrumen penjaringan data pokok Pendidikan Islam resmi dilingkup Direktorat Jenderal Pendidikan Islam, tentunya penerapan EMIS ini harus dipahami betul fungsi dan kegunaannya, terlebih lagi operator EMIS di lembaga pendidikan keagamaan dan pondok pesantren itu sendiri diharapkan mampu menjalankan substansinya dengan konsisten.1 Namun, masih terlihat bahwa penerapan EMIS di kementerian agama Kota Bangkalan ini masih belum optimal, penulis melihat lebih rinci belum optimalnya penerapan EMIS dilihat dari segi data lembaga yang tidak sesuai dengan kondisi riil dan pihak lembaga yang belum bisa mengoperasikan EMIS sebagaimana mestinya karena kendala dengan hal-hal yang lain seperti lembaga yang berada di pelosok dan sangat minim akan adanya sinyal dan lainlain. Hal tersebut menunjukkan bahwa penerapan EMIS masih belum optimal diterapkan pada Lembaga pendidikan diniyah dan pondok pesantren Kementerian Agama Bangkalan. Selain itu, pengumpulan data dari lembaga pendidikan diniyah dan pondok pesantren kurang menganggap pentingnya data EMIS sehingga

${ }^{1}$ Rasdiana Sina dkk, "Penerapan Education Management Information System (Emis) Di Lembaga Pendidikan Keagamaan Dan Pondok Pesantren Pada Kantor Kementerian Agama Kota Makassar", Journal of Public Policy and Management, Vol 1 No 1 Mei 2020 
masih terjadi keterlambatan dan tidak melengkapi data EMIS tepat pada waktunya sehingga menyebabkan keterlambatan terkumpulnya data-data lembaga pendidikan keagamaan dan pondok pesantren.

Setiap data EMIS diperbaharui secara berkala dengan tujuan diperolehnya informasi yang dapat mempermudah dalam mengontrol dan menganalisis informasi EMIS pada setiap lembaga pendidikan keagamaan dan Pondok Pesantren di Bangkalan. Namun dalam hal pengumpulan data masih terdapat kendala, yaitu masih kurangnya pemahaman pengelola yang kurang menganggap pentingnya data EMIS secara tepat waktu seperti pada beberapa lembaga pendidikan keagamaan dan Pondok Pesantren di kota Bangkalan. Hal tersebut berakibat pada terlambatnya pengumpulan data dari jadwal yang telah ditentukan dan juga mengakibatkan terhambatnya proses pelayanan pendidikan di lingkup pendidikan keagamaan dan pondok pesantren, sehingga diharapkan seluruh lembaga pendidikan keagamaan dan pondok pesantren mengisi data EMIS secara tepat waktu, lengkap dan akuntabel serta data EMIS harus ter-update secara periodik.

Melalui uraian latar belakang tersebut, penulis merasa tertarik untuk mengetahui sejauh mana penerapan EMIS di lembaga pendidikan diniyah dan pondok pesantren yang hingga saat ini belum optimal. Dengan demikian penulis menarik judul dalam penelitian ini yaitu Optimalisasi EMIS dalam Proses Data Base Pendidikan Diniyah dan Pondok Pesantren di Kementerian Agama Kabupaten Bangkalan.

\section{Education Management Information System (EMIS)}

EMIS Education Management Information System Merupakan sebuah Sistem informasi manajemen pendidikan untuk mendukung perencanaan dan pengambilan kebijakan program Pendidikan Islam. Sistem EMIS akan dikembangkan dengan menggunakan Aplikasi Berbasis Android sehingga dapat dengan mudah 
di akses oleh pengguna data (Direktorat Diktis, PTKIN, PTKIS, Kopertais, dan pengguna data lainnya). 2

Kementrian Agama yang bertanggung jawab terhadap pelaksanaan pendidikan Agama madrasah dan sekolah dalam pendataannya telah menggunakan sistem informasi manajemen pendidikan yang dikenal dengan EMIS (Education Management Information System). EMIS yang digunakan dalam lingkungan Kementrian Agama berisi informasi yang dibutuhkan dalam pengambilan keputusan bidang pendidikan. Sistem ini merekam tentang jumlah lembaga, pendidik dan tenaga kependidikan, fasilitas yang dimiliki, dan lain-lain.3 Emis digunakan sebagai pendukung pengambilan keputusan dalam lembaga pendidikan. System ini akan mengatur dan mengelola data yang ada di pendidikan.

Penggunaan EMIS dalam sistem informasi manajemen pendidikan di lingkungan kementerian Agama memiliki tujuan sebagai berikut. (1) Memperkuat kemampuan untuk mengatur, merencanakan, dan mengawasi alur informasi antar instansi yang saling berhubungan. (2) Memadukan seluruh informasi yang berhubungan dengan manajemen kegiatan pendidikan dan menyajikannya secara ringkas dan menyeluruh. (3) Memperbaiki kapasitas pengolahan, penyimpanan, dan analisis data dalam menyediakan informasi yang terpercaya dan tepat waktu bagi perencana, pemimpin, dan penanggungjawab bidang pendidikan. (4) Mengkoordinasikan proses pengumpulan, penyimpanan, pengolahan, analisis dan penyebaran informasi dalam manajemen pendidikan. (5) Memudahkan dan meningkatkan penggunaan informasi yang seseuai oleh berbagai instansi dan perorangan pada

${ }^{2}$ Aswin Viktor dkk, "System Informasi Pelaporan Data Emis Pada Institute Agama Islam Negeri Ternate Berbasis Android”, Program Studi Teknik Informatika, Universitas Muhammadiyah Maluku Utara Juni 2019

3 Evy Ramadina, "Pengelolaan Education Management Information System (Emis) Dalam Pengambilan Keputusan”, Jurnal System Informasi Indonesia Vol 2 No 12017 
semua jenjang agar perencanaan, pelaksanaan, dan manajemen pendidikan dapat lebih efektif.4

Dari beberapa uraian diatas dapat disimpulkan bahwa emis adalah system informasi manajemen pendidikan mengatur data dan informasi yang digunakan dalam pendidikan untuk mencapai tujuan yang maksimal dalam pemperolehan dan pengolahan data secara real dan akurat.

Sistem EMIS digunakan untuk mengatur data dan informasi pendidikan dalam jumlah besar yang dapat dibaca, diambil kembali, diproses, dianalisis, disajikan dan disebarkan.

Dari beberapa uraian diatas dapat disimpulkan bahwa emis adalah system informasi manajemen pendidikan mengatur data dan informasi yang digunakan dalam pendidikan untuk mencapai tujuan yang maksimal dalam pemperolehan dan pengolahan data secara real dan akurat.

Sistem EMIS digunakan untuk mengatur data dan informasi pendidikan dalam jumlah besar yang dapat dibaca, diambil kembali, diproses, dianalisis, disajikan dan disebarkan.

\section{Basis Data (Database)}

Database bila diterjemahkan kedalam bahasa Indonesia secara harafiah berarti pangkalan data. database selain sebagai tempat parkirnya data juga mempunyai bahasa programnya sendiri yang mempunyai kemampuan untuk tidak hanya memanipulasi data tapi juga untuk membangun suatu aplikasi website.5

Basis data (database) adalah kumpulan data yang disimpan secara sistematis didalam komputer yang dapat diolah atau dimanipulasi menggunakan perangkat lunak (program aplikasi) untuk menghasilkan informasi. Pendefinisian basis data meliputi spesifikasi berupa tipe data, struktur data dan juga batasan-batasan pada data yang akan disimpan. Basis data menjadi penting karena

\footnotetext{
${ }^{4}$ Fuadi Aziz, "Pengambilan Kebijakan Berbasis Education Management Information System EMIS”, Jurnal Pendidikan Islam, Vol IIII, No 1, Juni 2014

5 Helmy Kusuma, Database Oracle Untuk Pemula, (Eastern Light Publication, 2011)
} 
dapat mengorganisasi data, menghidari duplikasi data, menghindari hubungan antar data yang tidak jelas dan juga update yang rumit. (Erwan Arbi, 2000).6

Ahli lain Sutabri (2016) dalam buku Sistem Informasi Manajemen bahwa "Database adalah suatu kumpulan data terhubung (interrelated data) yang disimpan secara bersama-sama pada suatu media, tanpa mengatap satu sama lain atau tidak perlu suatu kerangkapan data (controlled redundancy".

Pengertian Database menurut Winarno dan Utomo "Database atau biasa disebut basis data merupakan kumpulan data yang saling berhubungan. Data tersebut biasanya terdapat dalam tabeltabel yang saling berhubungan satu sama lain, dengan menggunakan field/kolom pada tiap tabel yang ada".7

Dari beberapa pendapat di atas dapat diambil kesimpulan bahwa database merupakan kumpulan item data yang sudah tersimpan di dalam computer dan saling terhubung satu sama lain untuk menghasilkan sebuah informasi tanpa adanya duplikat data dan lebih efisien dalam mencari data yang diinginkan.

Alasan diperlukan Database adalah sebagai berikut:

- Salah satu komponen penting dalam sistem informasi, karena merupakan dasar dalam menyediakan informasi.

- Menentukan kualitas informasi yang akurat, tepat pada waktunya dan relevan. Informasi dapat dikatakan bernilai bila manfaatnya lebih efektif dibandingkan dengan biaya mendapatkannya.

- Mengurangi duplikasi data (data redudancy).

- Hubungan data dapat ditingkatkan (data relatability).

Pendidikan Diniyah dan Pondok Pesantren

\footnotetext{
${ }^{6}$ Aswin Viktor Dkk, "Sistem Informasi Pelaporan Data Emis Pada Institut Agama Islam Negeri Ternate Berbasis Android”, Program Studi Teknik Informatika Universitas Muhammadiyah Maluku Utara, Juni 2019.

7 Agus Prayitno dan Yulia Safitri, "Pemanfaatan Sistem Informasi Perpustakaan Digital Berbasis Website Untuk Para Penulis”, Lppm3.bsi.ac.id/jurnal, IJSE - Indonesian Journal on Software Engineering, Vol 1 No 1, 2015
} 
Madrasah Diniyah adalah lembaga pendidikan dan pengajaran agama Islam yang berfungsi untuk melaksanakan tugas yang utama sebagai seorang muslim, untuk merealisasikan pendidikan Agama terurama jenjang kitab klasik sesuai dengan tuntutan orang tua murid agar anak-anak lebih banyak mendapat pendidikan Agama Islam yang pada gilirannya nanti bisa mengamalkannya demi keselamatan mereka baik didunia maupun diakhirat kelak. 8

Perkembangan pendidikan pondok pesantren merupakan perwujudan dari kebutuhan masyarakat akan suatu system pendidikan alternative. Keberadaan pondok pesantren tersebut sebagai lembaga pendidikan, juga sebaiag lembaga dakwah dan syiar islam serta sosial keagamaan. Keberadaan pondok pesantren di Indonesia, dalam perkembangannya sangat berpengaruh terhadap masyarakat di sekitarnya, terutama dalam hal pendidikan. Hal ini disebabkan bahwa dari sejak awal berdirinya pesantren disiapkan untuk mendidik dan menyebarkan ajaran Islam kepada masyarakat melalui pengajian, baik dengan sistem tradisional maupun modern.

Perkataan pesantren berasal dari kata "santri", dengan awalan "pe" dan akhiran "an" yang mempunya arti asrama tempat santri atau tempat murid belajar mengaji . Berkaitan dengan istilah pondok pesantren, maka sebelum tahun 1960-an istilah "pondok" lebih dikenal sebagai pusat pendidikan pesantren. Menurut Zamakhsyari bahwa istilah pondok kemungkinan berasal dari pengertian asrama para santri atau tempat tinggal yang dibuat dari bambu, atau mungkin berasal dari kata Arab funduq yang berarti hotel atau asrama. Kata pondok dalam Kamus Besar Bahasa Indonesia adalah bangunan untuk tempat sementara; rumah; bangunan tempat tinggal yang berpetak yang berdinding bilik dan beratap rumbia; madrasah dan asrama (tempat mengaji, belajar agama Islam). Istilah pondok ataupun pesantren pada dasarnya memiliki makna yang sama yaitu tempat tinggal santri, namun

${ }^{8}$ M. Jamhuri, "Upaya Pendidikan Madrasah Diniyah dalam Meningkatkan Prestasi Belajar Siswa Pada Materi Fiqih di Madrasah Diniyah Miftahul Ulum Pruten Ngembal Pasuruan", Universitas Yudharta Pasuruan, Jurnal Pendidikan Agama Islam, Vol 2, No 2, Juni 2017 
penggunaan pondok pesantren sering digunakan oleh masyarakat yang dapat dipahami sebagai penguatan makna saja. 9

Dari pengertian lain Pondok pesantren adalah lembaga pendidikan tradisional Islam untuk mempelajari, memahami,mendalami, menghayati dan mengamalkan ajaran Islam dengan menekankan pentingnya moral keagamaan sebagai pedoman perilaku sehari-hari. Ajaran Islam tersebut menyatu dengan struktur kontekstual atau realitas sosial yang digumuli dalam kehidupan keseharian.10

Dapat disimpulakan bahwa pendidikan diniyah dan pondok pesantren adalah lembaga pendidikan berbasis islam untuk mempelajari, memahami dan mengamalkan ajaran-ajaran islam sehari-harinya.

\section{Metodologi}

\section{Jenis Penelitian}

Adapun jenis penelitian yang dilakukan menggunakan metode deskriptif kualitatif. Penelitian deskriptif yakni peneliti yang berupa pemecahan masalah yang ada berdasarkan fakta dan data-data. Jenis penelitian deksriptif kualitatif yang digunakan pada penelitian ini di maksudkan untuk menganalisis penerapan Education Managemen Information System (EMIS) di lembaga keagamaan pada kantor kementerian agaman kabupaten Bangkalan. Selain itu, dengan pendekatan kualitatif diharapkan dapat diungkapkan situasi dan permasalahan yang dihadapi dalam penerapan Education Managemen Information System (EMIS).

\section{Waktu dan Tempat Penelitian}

Waktu Penelitian: Kamis, 1 Oktober 2020 Tempat Penelitian: Pendidikan diniyah dan Pondok Pesantren pada Kantor

\footnotetext{
${ }^{9}$ B. Marjani Alwi, "PONDOK PESANTREN: Ciri Khas, Perkembangan, dan Sistem Pendidikannya, Fakultas Agama Islam Universitas Muhammadiyah Makassar", Lentera Pendidikan, Vol. 16 No. 2 Desember 2013

10 Rusydi Sulaiman, "PENDIDIKAN PONDOK PESANTREN: Institusionalisasi Kelembagaan Pendidikan Pesantren”, STAIN Syaikh Abdurrahman Siddik Bangka-Belitung, 'Anil Islam Vol 9 No 1, Juni 2016
} 
Kementerian Agama Bangkalan Jl. Soekarno Hatta No.9A, Wr 08, Mlajah Kecamatan Bangkalan, Kabupaten Bangkalan, Jawa Timur 69116.

\section{Sasaran Penelitian}

Dalam penelitian ini, yang menjadi sasaran penelitian atau objek oleh peneliti adalah pegawai pendidikan diniyah dan pondok pesantren Kementerian Agama Kabupaten Bangkalan.

\section{Instrumen Penelitian}

Instrumen penelitian yang digunakan pada penelitian ini yaitu melalui pedoman wawancara dan observasi.

\section{Teknik Pengumpulan Data}

\section{Wawancara}

Wawancara dilakukan kepada subjek penelitian dengan pedoman yang telah dibuat. Tekhnik wawancara digunakan untuk mengungkapkan data tentang penerapan data EMIS lembaga pendidikan diniyah dan Pondok Pesantren.

\section{Observasi}

Sebagaimana tujuan penelitian ini yang berupaya mengumpulkan data dengan melakukan observasi pada Kantor Kementerian Agama Bangkalan penerapan EMIS di lembaga pendidikan keagamaan dan Pondok Pesantren dilihat dari segi perilaku pengelola/operator dan proses kerja yang dilakukan dilingkungan Kementerian Agama Kabupaten Bangkalan sebagai penyelenggara EMIS.

\section{Dokumentasi}

Selain metode wawancara dan observasi sebagaimana yang telah dikemukakan diatas, dalam penelitian ini dilakukan pula metode dokumentasi.

\section{Teknik Analisis Data}

Penelitian ini adalah penelitian deskriptif yang beerbentuk uraian dari hasil yang telah didapatkan dengan wawancara dan studi dokumentasi. Data yang diperoleh ini akan dianalisis secara kualitatif serta diuraikan dalam bentuk deskriptif.

\section{Hasil dan Pembahasan}

Penerapan EMIS Pendidikan Diniyah dan Pondok Pesantren

Penerapan EMIS Pendidikan Diniyah dan Pondok Pesantren 
Penerapan EMIS pada pendidikan diniyah dan pondok pesantren merupakan sebuah upaya untuk memanfaatkan teknologi yang telah disediakan oleh Kementerian Agama Republik Indonesia. EMIS berfungsi untuk memberikan gambaran awal atau informasi tentang keadaan yang terjadi di lapangan. Dengan adanya EMIS ini pihak pendidikan diniyah dan pondok pesantren di Kementerian Agama Kabupaten Bangkalan bisa dengan mudah untuk mengetahui secara cepat jumlah murid dalam suatu lembaga, kondisi sarana prasarana, jumlah tenaga pendidik yang ada di suatu lembaga, angka kelulusan maupun rasio guru dan murid.

EMIS merupakan sebuah sistem yang dirancang dan dibiayai oleh negara. Maka, dengan adanya EMIS ini diharapkan bisa memberikan data yang akurat dan mudah untuk diakses, sehingga segala usaha yang telah dilakukan Kementerian Agama Republik Indonesia dalam melakukan pendataan pendidikan dapat dimanfaatkan dalam setiap pengambilan kebijakan.

Peranan pimpinan sangat berkontribusi dalam penerapan EMIS sesuai dengan arahan Kementerian Agama Kabupaten Bangkalan sebagai pihak yang bertanggung jawab pada penerapan EMIS. Pada penerapan EMIS ini seyogyanya harus ada koordinasi yang baik antar tiap unit kerja.

Berikut beberapa data lembaga yang telah melakakukan update EMIS di Kemeneterian Agama Kabupaten Bangkalan:

\begin{tabular}{|c|l|c|}
\hline Nama Lembaga & Jumlah Lembaga & $\begin{array}{c}\text { Lembaga yang } \\
\text { Sudah Update } \\
\text { EMIS }\end{array}$ \\
\hline PDF & 4 Lembaga & $100 \%$ \\
\hline PKPPS & 45 Lembaga & $100 \%$ \\
\hline $\begin{array}{c}\text { Pontren } \\
\text { Umum }\end{array}$ & 137 Lembaga & $40 \%$ \\
\hline TPQ & 216 Lembaga & $15 \%$ \\
\hline Madin & 1318 Lembaga & $10 \%$ \\
\hline
\end{tabular}

Dari data tersebut, dapat disimpulkan bahwa hanya lembaga PDF (Pendidikan Diniyah Formal) dan PKPPS (Pendidikan Kesetaraan Pondok Pesantren Salafiyah) yang sudah update EMIS secara keseluruhan. Sedangkan pondok pesantren umum yang 
melakukan update EMIS 40\%, Taman Pendidikan Al-Qur'an 15\% dan Madrasah Diniyah 10\%. Jadi, masih banyak lembaga yang belum melakukan update EMIS. Hal tersebut disebabkan oleh beberapa kendala.

Kendala-kendala yang dihadapi pada penerapan EMIS diantaranya:

\section{Faktor SDM (Sumber Daya Manusia)}

Keberhasilan dalam mengolah sebuah lembaga dipengaruhi oleh pengolahan sumber daya manusia dan hal teknis secara bersamaan. Operator lembaga pendidikan diniyah dan pondok pesantren akan memiliki tingkat kinerja yang baik jika terdapat kesesuaian antara pekerjaan dan kemampuan yang dimilikinya. Diperlukan adanya perasaan tanggung jawab terhadap pekerjaanya dan kesediaan untuk ikut berpartisipasi dalam mencapai tujuan dengan melaksanakan tugas-tugas yang diberikan.

Operator lembaga harus mempunyai keahlian/skill yang berupa kemahiran atas jenis pekerjaan yang dikerjakannya. Keahlian/skill yang harus dimilikinya seperti kompetensi dan kemampuan analitis serta kemampuan dalam menggunakan alat dan teknik dalam penerapan EMIS pendidikan diniyah dan pondok pesantren.

Seorang operator juga sangat penting untuk memiliki pengetahuan tentang sistem EMIS pendidikan diniyah dan pondok pesantren untuk pengambilan sebuah keputusan. Selain itu, diperlukan adanya motivasi diri agar tetap semangat dalam mengerjakan tugas-tugas dan tanggungjawabnya.. Faktanya di beberapa lembaga masih banyak yang belum memiliki Sumber Daya Manusia/operator sesuai dengan kriteria yang sudah dipaparkan di atas, sehingga hal tersebut menjadi kendala dalam penerapan EMIS pendidikan diniyah dan pondok pesantren.

\section{Faktor Sarana Prasarana}

Sarana prasarana sangat dibutuhkan dalam penunjang pendidikan, khususnya dalam penerapan EMIS pendidikan diniyah dan pondok pesantren. Tanpa adanya kelengkapan sarana prasarana, maka proses penerapan EMIS akan terhambat. Dalam penerapan EMIS ini dibutuhkan beberapa alat diantaranya computer/laptop, printer, modem/wifi dan lain sebagainya. Alat- 
alat ini merupakan salah satu alat yang secara khusus digunakan untuk keperluan penerapan EMIS pendidikan diniyah dan pondok pesantren. Kondisi yang ada di beberapa lembaga masih banyak sarana prasarana yang belum tersedia sehingga ada hambatan dalam penerapan EMIS.

\section{Faktor Jaringan}

Jaringan pendukung internet yang memadai sangat penting dalam penerapan EMIS untuk melakukan proses pendataan lembaga. Namun, di beberapa lembaga masih ditemukan perangkat pendukung jaringan internet sebagai pendukung utama dalam proses pengelolaan data EMIS. Hal tersebut dikarenakan banyak lembaga yang berada di pelosok atau pedalaman yang jaringannya kurang stabil.

\section{Proses Data Base pada EMIS}

Peran EMIS sebagai sebuah sistem informasi manajemen pendidikan yang digunakan oleh pendidikan diniyah dan pondok pesantren di Kementerian Agama Kabupaten Bangkalan adalah sebagai sumber data yang dapat digunakan sebagai pendukung pengambilan keputusan. Dalam pengambilan keputusan dibutuhkan data yang riil dan akurat.

\section{Kategori Data-data EMIS}

Data-data lembaga yang masih mentah diinput langsung oleh pihak lembaga atau operator lembaga pendidikan diniyah dan pondok pesantren melalui aplikasi EMIS berbasis web atau bisa melalui format data lain yang datanya bisa diintegrasikan dengan data base aplikasi EMIS online. Selanjutnya data mentah ini akan diolah menjadi sebuah informasi yang disajikan dalam bentuk publikasi. Dengan adanya informasi ini dapat bermanfaat sesuai kebutuhannya.

\section{Ketepatan Waktu Pendataan}

Dalam proses pendataan dibutuhkan banyak waktu dalam setiap proses pengerjaannya, karena seringkali adanya beberapa kendala, baik internal maupun eksternal. Namun operator lembaga harus berusaha agar data-data diisi dengan waktu yang telah ditetapkan. Dengan adanya sistem EMIS ini, dirasa sangat membantu dalam proses pengambilan keputusan dan bisa 
mempercepat kinerja di Kementerian Agama. Maka dari itu, diperlukan data yang valid, akurat, serta mudah untuk diakses untuk menentukan pengambilan keputusan oleh pihak yang bersangkutan.

\section{Aturan dalam Proses Pendataan}

Dalam proses pendataan sangat dibutuhkan adanya aturanaturan sebagai pedoman dalam langkah-langkah pengelolaan EMIS. Di dalam aturan-aturan proses pendataan, perlu adanya koordinasi yang baik dengan semua pihak yang memanfaatka peranan EMIS di Kementerian Agama Kabupaten Bangkalan. Pedoman atau aturan yang telah dibuat akan selalu diadakan perbaikan atau pembaharuan sesuai situasi, kondisi dan fakta riil yang terjadi di lapangan.

\section{Kesimpulan}

Emis education management information system diartikan bahwa emis adalah system informasi manajemen pendidikan mengatur data dan informasi yang digunakan dalam pendidikan untuk mencapai tujuan yang maksimal dalam pemperolehan dan pengolahan data secara real dan akurat. EMIS berfungsi untuk memberikan gambaran awal atau informasi tentang keadaan yang terjadi di lapangan. Hanya lembaga PDF (Pendidikan Diniyah Formal) dan PKPPS (Pendidikan Kesetaraan Pondok Pesantren Salafiyah) yang sudah update EMIS secara keseluruhan. Sedangkan pondok pesantren umum yang melakukan update EMIS 40\%, Taman Pendidikan Al-Qur'an 15\% dan Madrasah Diniyah 10\%. Masih banyak lembaga yang belum melakukan update EMIS. Hal tersebut disebabkan oleh beberapa kendala, seperti faktor SDM (Sumber Daya Manusia), faktor sarana prasarana, faktor jaringan.

Data base atau basic data merupakan kumpulan item data yang sudah tersimpan di dalam computer dan saling terhubung satu sama lain untuk menghasilkan sebuah informasi tanpa adanya duplikat data dan lebih efisien dalam mencari data yang diinginkan. Data-data lembaga akan diolah menjadi sebuah informasi yang disajikan dalam bentuk publikasi. Dengan adanya sistem EMIS ini, dirasa sangat membantu dalam proses pengambilan keputusan dan bisa mempercepat kinerja di Kementerian Agama, sehingga 
dibutuhkan data yang valid, akurat, serta mudah untuk diakses untuk menentukan pengambilan keputusan.

Madrasah Diniyah adalah lembaga pendidikan dan pengajaran agama Islam yang berfungsi untuk melaksanakan tugas yang utama sebagai seorang muslim, untuk merealisasikan pendidikan Agama Pendidikan diniyah dan pondok pesantren adalah lembaga pendidikan berbasis islam untuk mempelajari, memahami dan mengamalkan ajaran-ajaran islam sehari-harinya.

Seksi pendidikan diniyah dan pondok pesantren perlu mengadakan pelatihan khusus aplikasi EMIS, agar pihak lembaga yang bersangkutan lebih memahami bagaimana mengaplikasikan EMIS dengan baik dan benar, sehingga lembaga yang bersangkutan bisa dengan mudah melakukan update EMIS.

Pihak lembaga seharusnya menyediakan sumber daya manusia atau operator yang memiliki keahlian/skill, memiliki pengetahuan tentang sistem EMIS. Disarankan untuk pihak lembaga agar melengkapi data-data yang ada di sistem EMIS.

\section{References}

Alwi, B. Marjani, "PONDOK PESANTREN: Ciri Khas, Perkembangan, dan Sistem Pendidikannya, Fakultas Agama Islam Universitas Muhammadiyah Makassar", Lentera Pendidikan, Vol. 16 No. 2 Desember 2013

Aziz, Fuadi, "Pengambilan Kebijakan Berbasis Education Management Information System EMIS", Jurnal Pendidikan Islam, Vol IIII, No 1, Juni 2014

Jamhuri, M. “Upaya Pendidikan Madrasah Diniyah dalam Meningkatkan Prestasi Belajar Siswa Pada Materi Fiqih di Madrasah Diniyah Miftahul Ulum Pruten Ngembal Pasuruan", Universitas Yudharta Pasuruan, Jurnal Pendidikan Agama Islam, Vol 2, No 2, Juni 2017

Kusuma, Helmy, Database Oracle Untuk Pemula, (Eastern Light Publication, 2011) 
Minarni dan Susanti, "Sistem Informasi Inventory Obat Pada Rumah Sakit Umum Daerah (RSUD) Padang", Jurnal Momentum, Vol 16 No 1, Februari 2014

Prayitno, Agus dan Safitri, Yulia "Pemanfaatan Sistem Informasi Perpustakaan Digital Berbasis Website Untuk Para Penulis", Lppm3.bsi.ac.id/jurnal, IJSE - Indonesian Journal on Software Engineering, Vol 1 No 1, 2015

Ramadina, Evy, "Pengelolaan Education Management Information System (Emis) Dalam Pengambilan Keputusan", Jurnal System Informasi Indonesia Vol 2 No 12017

Sina, Rasdiana dkk, "Penerapan Education Management Information System (Emis) Di Lembaga Pendidikan Keagamaan Dan Pondok Pesantren Pada Kantor Kementerian Agama Kota Makassar", Journal of Public Policy and Management, Vol 1 No 1 Mei 2020

Sulaiman, Rusydi "PENDIDIKAN PONDOK PESANTREN: Institusionalisasi Kelembagaan Pendidikan Pesantren", STAIN Syaikh Abdurrahman Siddik Bangka-Belitung, 'Anil Islam Vol 9 No 1, Juni 2016

Viktor, Aswin Dkk, "Sistem Informasi Pelaporan Data Emis Pada Institut Agama Islam Negeri Ternate Berbasis Android", Program Studi Teknik Informatika Universitas Muhammadiyah Maluku Utara, Juni 2019. 